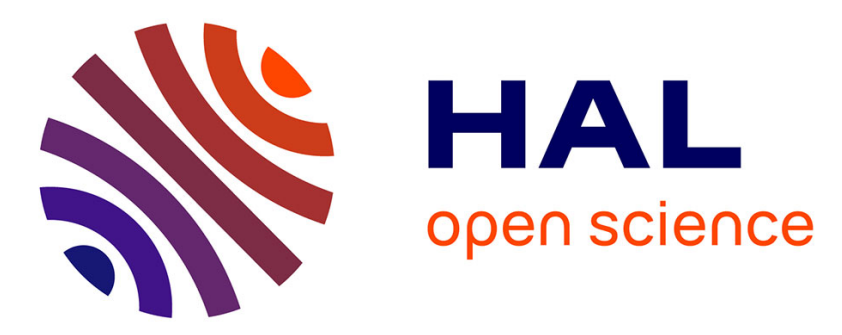

\title{
Epoxidized Oleic Acid-Based Polymethacrylates as Viscosity Index Improvers
}

Juliette Lomège, Vincent Lapinte, Claire Negrell, Jean-jacques Robin, Sylvain Caillol

\section{- To cite this version:}

Juliette Lomège, Vincent Lapinte, Claire Negrell, Jean-jacques Robin, Sylvain Caillol. Epoxidized Oleic Acid-Based Polymethacrylates as Viscosity Index Improvers. Journal of the American Oil Chemists' Society, 2019, 96 (4), pp.467-478. 10.1002/aocs.12187 . hal-02088457

\section{HAL Id: hal-02088457 https://hal.science/hal-02088457}

Submitted on 15 May 2020

HAL is a multi-disciplinary open access archive for the deposit and dissemination of scientific research documents, whether they are published or not. The documents may come from teaching and research institutions in France or abroad, or from public or private research centers.
L'archive ouverte pluridisciplinaire HAL, est destinée au dépôt et à la diffusion de documents scientifiques de niveau recherche, publiés ou non, émanant des établissements d'enseignement et de recherche français ou étrangers, des laboratoires publics ou privés. 


\title{
Epoxidized oleic acid-based polymethacrylates as viscosity index improvers
}

Juliette Lomège, Vincent Lapinte, Claire Negrell, Jean-Jacques Robin, Sylvain Caillol*

Institut Charles Gerhardt Montpellier UMR 5253, Univ Montpellier CNRS ENSCM, Université de Montpellier, CC1702, Place Eugène Bataillon, 34095 Montpellier Cedex 5, France.

* Correspondence to: S. Caillol: sylvain.caillol@enscm.fr

Keywords: Oleic acid; Epoxidation; Radical polymerization; Rheology; Lubricant; Viscosity Index Improver

\begin{abstract}
This study reports two routes for the synthesis of epoxidized oleic acid-based polymethacrylates. The first one consisted in the synthesis followed by epoxidation of the oleic acid-based methacrylate, 2-(methacryloyloxy)ethyl oleate (MAEO) prior its radical polymerization. In the second pathway, MAEO was firstly homopolymerized to afford poly(2-(methacryloyloxy)ethyl oleate) (PMAEO) and, then, the internal double bonds of the oleate were epoxidized at different yields ranging from 20 to $100 \%$. All polymeric structures were confirmed by ${ }^{1} \mathrm{H}$ NMR, and characterized through SEC, TGA and DSC analyses. The resulting polymers were then blended at $5 \mathrm{wt}$ \% in a mineral paraffinic (MPO) oil and in a biobased organic triglyceride oil (OTO) in order to be evaluated as VII. The partially epoxidized polymers up to $40 \%$ were soluble in MPO. According to a rheological study, the oil-soluble epoxidized polymers resulting from the epoxidation of PMAEO exhibited a much higher influence on oil viscosities at high than at low temperatures compared to the low epoxidized PMAEO molecular weight obtained by the first strategy. Additionally, the viscosity index of both lubricating oils were significantly improved with the addition of the epoxidized oleic acid-based polymers resulting from the epoxidation of PMAEO which confirmed their efficiency as VII.
\end{abstract}




\section{Graphical abstract:}

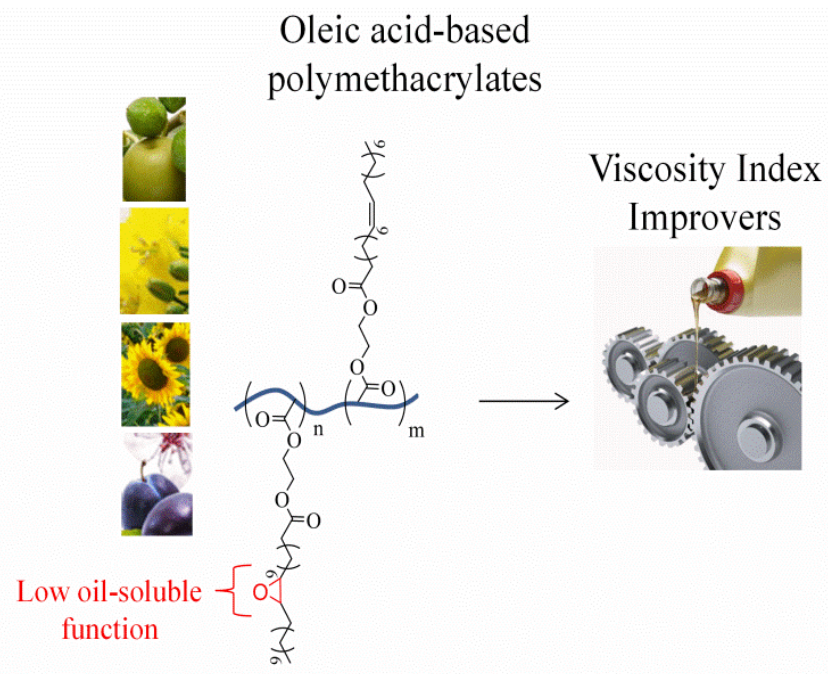

\section{Introduction}

Multi-grade engine lubricating oils are subject to a wide range of operating temperatures. ${ }^{1,2}$ Therefore, one of the most essential requirements for such lubricating oils is to exhibit a low enough viscosity at low temperatures to maintain pumpability as well as a high enough viscosity at high temperatures to provide a sufficient film strength. ${ }^{3}$ In the lubricant field, the variation of viscosity with temperature is expressed by the value of the viscosity index (VI). ${ }^{4}$ The method consists in comparing the kinematic viscosity of the fluid to that of two reference fluids at 40 and $100{ }^{\circ} \mathrm{C} .{ }^{5}$ Oils with a high VI exhibit a much smaller viscosity-temperature dependence than oils with a lower VI.

For many decades, the VI of mineral oils which have low VI, has been improved by adding polymeric viscosity index improvers (VII) in lube oils which ensured a proper oil viscosity at high temperature. ${ }^{6-8}$ The most commonly used polymers in lubricant applications are poly(alkyl methacrylate)s (PMA)s. ${ }^{9-11}$ Such polymers are less soluble than hydrocarbon polymers in mineral oils due to their polar ester functions and are known to raise the viscosity of the mineral oil proportionately more at high than at low temperatures which results in the lube oil VI improvement. ${ }^{10,12,13}$ Their widely reported mechanism of action is based on the coil polymer expansion in mineral oil which is assimilated to the gradual improvement of polymers solubility in temperature and therefore to a gradual polymer thickening power in oil. ${ }^{14-16}$ Despite their extensive use in lubricant applications, the monomers used to afford PMAs belong to the second generation of petrochemical products. Indeed, PMAs are mainly 
copolymers based on low oil-soluble alkyl methacrylates $\left(<\mathrm{C}_{7}\right)$ and long oil-soluble alkyl alcohol methacrylates $\left(\mathrm{C}_{12}-\mathrm{C}_{20}\right)$. All these monomers are mostly issued from petro-based resources, which can lead to environmental concerns in the next few years. ${ }^{17,18}$. Recently, due to their specific structure with long aliphatic chains combined with a polar head, VO-based polymers resulting from direct radical polymerization have shown promising properties as VII in various mineral lube oils ${ }^{28-30}$. However, even if they demonstrated good properties to enhance the field service performance of engine oil, VO generally showed poor reactivity in radical process. ${ }^{31}$ In most of the cases, VO required to be radically copolymerized with more reactive petrosourced comonomers to perform radical polymerization which decreases the ecological advantage of the resulting VO-based additives. ${ }^{32-34}$

Hence, beyond the functionalization of VO for the synthesis of reactive building blocks for step growth polymerization, some teams have design new fatty-acid based radically polymerizable mono-functional monomers ${ }^{35}$. These new VO-based monomers allowed the preparation of biobased polyacrylates with well-defined architectures which is not possible with conventional poylcondensation. Indeed, recently, Maiti et al. reported a new method of functionalization involving Steglich esterification of various FA (caprylic, capric, lauric, myristic, palmitic, stearic and oleic acids) to provide partially biobased methacrylate monomers in a one-step method. ${ }^{36,37}$ Another synthetic route based on a two-step method through amidation followed by (meth)acrylation has been recently reported by Yuan et al. to provide monomers for radical polymerization. ${ }^{38}$ Similarly, in order to find other bioalternative, our previous work focused on the synthesis of oleic acid- based monomer, the 2-(methacryloyloxy)ethyl oleate (MAEO), which was successfully involved in free radical polymerization (FRP) and evaluated as VII. ${ }^{19}$ The resulting homopolymer (PMAEO) has demonstrated good VII properties when blended (1-10 wt. \%) in a paraffinic mineral oil (MPO). However, when PMAEO was blended in an organic biobased triglyceride oil (1-10 wt. \%), the lubricating oil acted as a too "good solvent" at low temperature which prevented the coil polymer to further expand with temperature. It resulted in a similar thickening effect on oil viscosity at low and high temperatures instead of expected VII properties. ${ }^{39}$

Considering the growing production of biobased lubricants in the recent years, the use of PMAEO has been also extended in a triglyceride organic oil (OTO) to evaluate its efficiency as VII in a biolubricant. However, the polymer behaved as a simple thickener additive due to its too good solubility in the triglyceride oil at low temperature which prevented the coil polymer to further expand with temperature. By consequence, a same polymer will not 
necessarily be a good VII for oils with different compositions. Therefore, there is a major challenge in developing suitable VII for all types of lubricants and more especially for biolubricants. ${ }^{20-23}$

This study proposes to improve PMAEO properties as VII in MPO and, more especially, to extend its VII properties in a triglyceride oil (OTO). The strategy consists to customize the PMAEO with low oil-soluble function in order to decrease its initial solubility in both lube oils at low temperature. Thus, it may promote the coil polymer expansion by improving the difference of polymer solubility in lube oils at low and high temperatures and therefore may result in higher VII performances. For this purpose, two synthetic routes were investigated to afford a modified PMAEO with a reduced solubility in lube oils. In a first strategy, MAEO was epoxidized with hydrogen peroxide and formic acid and then involved in radical polymerization. The second strategy consisted in the direct fully and partially epoxidation of the polymer PMAEO. Finally, the resulting epoxidized polymers were evaluated and compared as VII in both OTO and MPO lubricating oils by measuring the dynamic viscosity of oil-polymer blends versus temperature. Further calculations of oil-polymer blends viscosity index were also conducted and compared to those of pure oils.

\section{Materials and methods}

\subsection{Reagents}

Oleic acid (OA, $98 \%)$ was obtained from Fisher Scientific. Dicyclohexylcarbodiimide (DCC, $99 \%$ ), 4-dimethylaminopyridine (DMAP, 99 \%), 2-hydroxyethyl methacrylate (HEMA, $98 \%$ ), hydrogen peroxide solution $30 \%$ in $\mathrm{H}_{2} \mathrm{O}\left(\mathrm{H}_{2} \mathrm{O}_{2}\right)$, p-toluenesulfonic acid monohydrate (p-TsOH, $98 \%$ ), benzoyl peroxide ( $\mathrm{BPO}$, with $25 \% \mathrm{H}_{2} \mathrm{O}$ ), and deuterated chloroform $\left(\mathrm{CDCl}_{3}, 99.8 \%\right)$ were purchased from Sigma-Aldrich. All solvents including tetrahydrofuran (THF, $99 \%)$, toluene (99.5\%), methanol (MeOH, $99.8 \%)$, ethyl acetate (EtOAc, $98 \%$ ) and cyclohexane (CY, $98 \%$ ) were purchased from VWR. Formic acid solution $60 \%$ in $\mathrm{H}_{2} \mathrm{O}$ was purchased from ICKOWICZ manufacturer. Based oils including an organic triglyceride oil (OTO) and a mineral paraffinic oil (MPO) were kindly supplied by ITERG and CHEVRON and their characteristics are detailed in Table 1. All products were used as received. 
Table 1: Base oils properties

\begin{tabular}{ccc}
\hline Properties & OTO & MPO \\
& & \\
\hline Density at $20{ }^{\circ} \mathbf{C}\left(\mathbf{g . c m}^{-3}\right)$ & 0.9273 & 0.8503 \\
Kinematic viscosity at $\mathbf{4 0}{ }^{\circ} \mathbf{C}\left(\mathbf{m m}^{2} . \mathbf{s}^{-1}\right)$ & $26.50^{*}$ & $26.92^{*}$ \\
Kinematic viscosity at $\mathbf{1 0 0}{ }^{\circ} \mathbf{C}\left(\mathbf{m m}^{2} . \mathbf{s}^{-1}\right)$ & $5.58^{*}$ & $4.87^{*}$ \\
Viscosity Index & 156 & 102 \\
Pour Point $\left({ }^{\circ} \mathbf{C}\right)$ & -30 & -15 \\
\hline
\end{tabular}

*measured through rheological measurements (see instrumentation part below)

\subsection{Instrumentations}

\section{Nuclear magnetic resonance (NMR)}

${ }^{1} \mathrm{H}$ NMR spectra were acquired using a Bruker Avance $400 \mathrm{MHz}$ spectrometer equipped with a QNP z-gradient probe at room temperature. NMR samples were prepared as follows: $10 \mathrm{mg}$ of product for ${ }^{1} \mathrm{H}$ experiment in around $0.4 \mathrm{~mL}$ of $\mathrm{CDCl}_{3}$. The chemical shifts were reported in part per million relative to tetramethylsilane. Spin multiplicity is expressed by $\mathrm{s}=$ singlet, $\mathrm{d}=$ doublet, $\mathrm{t}=$ triplet, $\mathrm{q}=$ quartet, $\mathrm{m}=$ multiplet

\section{Size exclusion chromatography (SEC)}

Molar mass and molar mass distribution (dispersity, Đ) of polymers were determined by size exclusion chromatography using a GPC 50 Varian equipped with an RI refractive index detector. The system used two PLgel $5 \mu \mathrm{m}$ Mixed D columns with THF as eluent with a flow rate of $1 \mathrm{~mL} \cdot \mathrm{min}^{-1}$. Poly(methyl methacrylate) (PMMA) standards were used for the calibration. The typical sample concentration was $5 \mathrm{mg} \cdot \mathrm{mL}^{-1}$.

\section{Thermogravimetric analysis (TGA)}

Thermogravimetric analyses (TGA) were performed using a TGA Q50 (TA instrument) at a heating rate of $10{ }^{\circ} \mathrm{C} \cdot \mathrm{min}^{-1}$. Approximately $10 \mathrm{mg}$ of sample were placed in an aluminum pan and heated from room temperature to $500{ }^{\circ} \mathrm{C}$ under nitrogen atmosphere $\left(60 \mathrm{~mL} \cdot \mathrm{min}^{-1}\right)$.

\section{Differential scanning calorimetry (DSC)}

Differential scanning calorimetry (DSC) analyses were carried out using a NETZSCH Maia DSC200F3 calorimeter. Constant calibration was performed using indium, $n$-octadecane and $n$-octane standards. Nitrogen was used as the purge gas. 10-15 mg samples were sealed in aluminum pans. The thermal properties were analyzed at $20{ }^{\circ} \mathrm{C} \cdot \mathrm{min}^{-1}$ between -100 and 100 ${ }^{\circ} \mathrm{C}$.

\section{Rheometer}


Rheological investigations are executed by using a MCR 302 rheometer by Anton-Paar in plate-plate geometry with a diameter of $\mathrm{d}=25 \mathrm{~mm}$. The dynamic viscosity of oil-polymer blends was measured from 0 to $100{ }^{\circ} \mathrm{C}$ at a shear rate of $100 \mathrm{~s}^{-1}$ and the relative viscosity $(\mathrm{RV})$ in function of temperature was calculated by using the equation below:

$$
R V=\frac{\mu}{\mu_{0}} \quad \text { Equation } 1
$$

where $\mu$ and $\mu_{0}$ correspond respectively to the dynamic viscosity of the polymer solution and the dynamic viscosity of the pure solvent.

\section{Densimeter}

Density measurements of all formulations were performed on the DMA 4100M densimeter of Anton Paar at 40 and $100{ }^{\circ} \mathrm{C}$. Before starting the test, the oil-polymer blends were all stirred at $100{ }^{\circ} \mathrm{C}$ during 1 hour to ensure a good homogenization. Then, samples were cooled at the temperature of measurement and approximatively $1 \mathrm{~mL}$ is loaded into the densimeter to start the test. The kinematic viscosity of oil-polymer blends at 40 and $100{ }^{\circ} \mathrm{C}$ were then deducted by following the equation:

$$
v=\frac{\mu}{\rho} \quad \text { Equation } 2
$$

where $v, \mu$, and $\rho$ correspond respectively to the fluid kinematic viscosity $\left(\mathrm{mm}^{2} \cdot \mathrm{s}^{-1}\right)$, the fluid dynamic viscosity $\left(\mathrm{Pa}_{\mathrm{s}}{ }^{-1}\right)$, and the fluid density $\left(\mathrm{g} . \mathrm{cm}^{-3}\right)$. Finally, the viscosity indexes of the formulations were calculated according to the ASTM D2270-10 method by using the values of kinematic viscosity of polymer solutions at 40 and $100{ }^{\circ} \mathrm{C}$.

\subsection{Preparation of methacrylate monomers from oleic acid and their resulting polymers}

\subsubsection{2-(methacryloyloxy)ethyloleate (MAEO)}

The synthesis procedure is exactly the same than described in our previous study. ${ }^{19}$

$\delta(\mathrm{ppm}): 6.12$ and $5.59\left(-\mathrm{C}=\mathrm{CH}_{2}, 2 \mathrm{H}, \mathrm{s}\right), 5.38-5.29(-\mathrm{CH}=\mathrm{CH}-, 2 \mathrm{H}, \mathrm{m}), 4.36-4.3(-$ $\left.\mathrm{OCH}_{2} \mathrm{CH}_{2} \mathrm{O}, 4 \mathrm{H}, \mathrm{m}\right), 2.32\left(\mathrm{O}=\mathrm{CCH}_{2}, 2 \mathrm{H}, \mathrm{t}, J=7.5 \mathrm{~Hz}\right), 2.05-1.98\left(-\mathrm{CH}_{2} \mathrm{CH}=\mathrm{CHCH}, 4 \mathrm{H}\right.$, m), $1.95\left(-\mathrm{CH}_{2}=\mathrm{C}-\mathrm{CH}_{3}, 3 \mathrm{H}, \mathrm{s}\right), 1.66-1.58\left(\mathrm{O}=\mathrm{CCH}_{2} \mathrm{CH}_{2}, 2 \mathrm{H}, \mathrm{m}\right), 1.29-1.26\left(\mathrm{CH}_{3}-\left(\mathrm{CH}_{2}\right)_{6^{-}}\right.$ $\left.\mathrm{CH}_{2}-\mathrm{CH}=\mathrm{CH}-\mathrm{CH}_{2}-\left(\mathrm{CH}_{2}\right)_{4}-, 2 \mathrm{H}, \mathrm{m}\right), 0.87\left(-\mathrm{CH}_{2} \mathrm{CH}_{3}, 3 \mathrm{H}, \mathrm{t}, J=6.9 \mathrm{~Hz}\right)$. Its chemical 
structure was confirmed by ${ }^{1} \mathrm{H}$ NMR $\left(400 \mathrm{MHz}, \mathrm{CDCl}_{3}\right)$. All peaks have been assigned as illustrated in Figure 1, (A).

\subsubsection{Epoxidized 2-(methacryloyloxy)ethyloleate (MAEO-E):}

MAEO (25.3 mmol, $10.0 \mathrm{~g}), 60 \%$ formic acid (27.8 mmol, $2.08 \mathrm{~g}), p$-TsOH (0.9 mmol, $0.15 \mathrm{~g})$ and toluene $(12 \mathrm{~mL})$ were introduced into a $50 \mathrm{~mL}$ round bottom flask equipped with a magnetic stirrer and reflux condenser. Then, the reaction mixture was heated at $50{ }^{\circ} \mathrm{C}$ and $30 \%$ aqueous hydrogen peroxide solution $(252.5 \mathrm{mmol}, 8.6 \mathrm{~g})$ was slowly added to the reaction. After complete addition of hydrogen peroxide, the reaction was slowly heated up to $65{ }^{\circ} \mathrm{C}$ during $4 \mathrm{~h}$. At the end of the reaction, the crude product was filtered and washed with a 5 wt.\% sodium bicarbonate solution and distilled water, respectively. Then, the organic phase was dried under vacuum at $65{ }^{\circ} \mathrm{C}$ for $3 \mathrm{~h}$ (yield $=64 \%$ ). The resulting monomer chemical structure was confirmed by ${ }^{1} \mathrm{H}$ NMR. All peaks have been assigned as illustrated in Figure $1,(\mathrm{~B})$.

$\delta(\mathrm{ppm}): 6.12$ and $5.59\left(-\mathrm{C}=\mathrm{CH}_{2}, 2 \mathrm{H}, \mathrm{s}\right), 4.36-4.30\left(-\mathrm{OCH}_{2} \mathrm{CH}_{2} \mathrm{O}, 4 \mathrm{H}, \mathrm{m}\right), 2.90-2.88(\mathrm{CH}-$ $\mathrm{O}-\mathrm{CH}-, 2 \mathrm{H}, \mathrm{m}), 2.32\left(\mathrm{O}=\mathrm{CCH}_{2}, 2 \mathrm{H}, \mathrm{t}, J=7.5 \mathrm{~Hz}\right), 1.95\left(-\mathrm{CH}_{2}=\mathrm{C}-\mathrm{CH} \mathbf{H}_{3}, 3 \mathrm{H}, \mathrm{s}\right), 1.58-1.66$ $\left(\mathrm{O}=\mathrm{CCH}_{2} \mathrm{CH}_{2}, 2 \mathrm{H}, \mathrm{m}\right), 1.50-1.45\left(\mathrm{CH}_{2}-\mathrm{CH}-\mathrm{O}-\mathrm{CH}-\mathrm{CH}_{2}, 4 \mathrm{H}, \mathrm{m}\right), 1.29-1.26\left(\mathrm{CH}_{3}-\left(\mathrm{CH}_{2}\right)_{6}{ }^{-}\right.$ $\left.\mathrm{CH}_{2}-\mathrm{CH}-\mathrm{O}-\mathrm{CH}-\mathrm{CH}_{2}-\left(\mathrm{CH}_{2}\right)_{4^{-}}, 2 \mathrm{H}, \mathrm{m}\right), 0.87\left(-\mathrm{CH}_{2} \mathrm{CH}_{3}, 3 \mathrm{H}, \mathrm{t}, J=6.9 \mathrm{~Hz}\right)$.

\subsubsection{Poly(2-(methacryloyloxy)ethyloleate) (PMAEO)}

The synthesis procedure is exactly the same than described in our previous study. ${ }^{19}$

$\delta$ (ppm): 5.38-5.29 $(-\mathrm{CH}=\mathrm{CH}-, 2 \mathrm{H}, \mathrm{m}), 4.25-4.13\left(-\mathrm{OCH}_{2} \mathrm{CH}_{2} \mathrm{O}-, 4 \mathrm{H}, \mathrm{m}\right), 2.37-2.27$ $\left(\mathrm{O}=\mathrm{CCH}_{2}, 2 \mathrm{H}, \mathrm{m}\right), 2.05-1.94\left(-\mathrm{CH}_{2} \mathrm{CH}=\mathrm{CHCH}_{2}-, 4 \mathrm{H}, \mathrm{m}\right), 1.82-1.61\left(-\mathrm{CH}_{2}-\mathrm{C}, 2 \mathrm{H}, \mathrm{m}\right), 1.62-$ $1.59\left(\mathrm{O}=\mathrm{CCH}_{2} \mathrm{CH}_{2}, 2 \mathrm{H}, \mathrm{m}\right), 1.31-2.27\left(-\left(\mathrm{CH}_{2}\right)_{6}-\mathrm{CH}_{2}-\mathrm{CH}=\mathrm{CH}-\mathrm{CH}_{2}-\left(\mathrm{CH}_{2}\right)_{4}-, 20 \mathrm{H}, \mathrm{m}\right), 1.03-$ $0.87\left(-\mathrm{CH}_{3}, 3 \mathrm{H}, \mathrm{m}\right), 0.87\left(-\mathrm{CH}_{2} \mathrm{CH}_{3}, 3 \mathrm{H}, \mathrm{t}, J=6.8 \mathrm{~Hz}\right)$. Its chemical structure was confirmed by ${ }^{1} \mathrm{H}$ NMR. All peaks have been assigned as illustrated in Figure 3, (A).

\subsubsection{Epoxidized poly(2-(methacryloyloxy)ethyloleate) (PMAEO-E)}

MAEO-E (12.70 mmol, $5.00 \mathrm{~g})$ and BPO $(0.25 \mathrm{mmol}, 61.00 \mathrm{mg})$ were dissolved in toluene $(25.0 \mathrm{~mL})$ in a two necked flask purged with $\mathrm{N}_{2}$ gas for $20 \mathrm{~min}$. The reaction mixture was heated at $90{ }^{\circ} \mathrm{C}$. After $24 \mathrm{~h}$, the polymerization was quenched by cooling the reaction mixture 
in liquid nitrogen. Then, the resulting fully epoxidized polymer was purified by several precipitations in cold $\mathrm{MeOH}$ and dried under vacuum for $5 \mathrm{~h}$ at $80{ }^{\circ} \mathrm{C}$ to get a viscous liquid (yield $=60 \%$ ). Its chemical structure was confirmed by ${ }^{1} \mathrm{H}$ NMR. All peaks have been assigned as illustrated in Figure 1, (B).

$\delta$ (ppm): 4.25-4.15 (- $\left.\mathrm{OCH}_{2} \mathrm{CH}_{2} \mathrm{O}-, 4 \mathrm{H}, \mathrm{m}\right), 2.91-2.86(\mathrm{CH}-\mathrm{O}-\mathrm{CH}-, 2 \mathrm{H}, \mathrm{m}), 2.34-2.30$ $\left(\mathrm{O}=\mathrm{CCH}_{2}, 2 \mathrm{H}, \mathrm{m}\right), 1.82-1.61\left(-\mathrm{CH}_{2}-\mathrm{C}, 2 \mathrm{H}, \mathrm{m}\right), 1.62-1.59\left(\mathrm{O}=\mathrm{CCH}_{2} \mathrm{CH}_{2}, 2 \mathrm{H}, \mathrm{m}\right), 1.50-1.45$ $\left(\mathrm{CH}_{2}-\mathrm{CH}-\mathrm{O}-\mathrm{CH}-\mathrm{CH}_{2}, 4 \mathrm{H}, \mathrm{m}\right), 1.34-1.26\left(-\left(\mathrm{CH}_{2}\right)_{6}-\mathrm{CH}_{2}-\mathrm{CH}=\mathrm{CH}-\mathrm{CH}_{2}-\left(\mathrm{CH}_{2}\right)_{4}-, 20 \mathrm{H}, \mathrm{m}\right)$, $1.02-0.89\left(-\mathrm{CH}_{3}, 3 \mathrm{H}, \mathrm{m}\right), 0.89\left(-\mathrm{CH}_{2} \mathrm{CH}_{3}, 3 \mathrm{H}, \mathrm{t}, J=6.8 \mathrm{~Hz}\right)$.

\subsubsection{Post-polymerization epoxidation of PMAEO}

PMAEO (20.20 mmol, $8 \mathrm{~g}$, 1eq), $60 \%$ aqueous $\mathrm{HCOOH}$ solution, $p$-TsOH (0.019 eq) and toluene $(12 \mathrm{~mL})$ were charged into a $50 \mathrm{~mL}$ round bottom flask equipped with a magnetic stirrer and reflux condenser. Then, the reaction mixture was heated at $50{ }^{\circ} \mathrm{C}$ and $30 \%$ aqueous hydrogen peroxide $\left(\mathrm{H}_{2} \mathrm{O}_{2}\right)$ solution was slowly added to the reaction. After complete addition of hydrogen peroxide, the reaction was slowly heated up to $65^{\circ} \mathrm{C}$. Five molar ratios of PMAEO:HCOOH: $\mathrm{H}_{2} \mathrm{O}_{2}$ were conducted (1:0.28:0.28; 1:0.38:0.38; 1:0.45:0.45; $1: 0.58: 0.58 ; 1: 1.1: 1.1 ;$ ) to target various yields of epoxidation ; 20, 30, 40, 50 and $100 \%$ respectively. The resulting polymers, respectively PMAEO-E ${ }_{20}$, PMAEO-E 30, PMAEO-E 40 , PMAEO-E $_{50}$, PMAEO-E ${ }_{100}$ were obtained respectively at $75 \%, 82 \%, 81 \%, 84 \%$ and $84 \%$ yields. Their chemical structures were all confirmed by ${ }^{1} \mathrm{H}$ NMR as illustrated in Figure 3, (A).

$\delta$ (ppm): 5.38-5.29 (-CH=CH-, 2H, m), 4.25-4.13 $\left(-\mathrm{OCH}_{2} \mathrm{CH}_{2} \mathrm{O}-, 4 \mathrm{H}, \mathrm{m}\right), 2.91-2.86(-\mathrm{CH}-$ O-CH-, 2H, m), 2.37-2.29 (O=CCH $\left.\mathbf{2}^{-}, 2 \mathrm{H}, \mathrm{m}\right), 2.07-1.95$ ( $\left.-\mathrm{CH}_{2} \mathrm{CH}=\mathrm{CHCH} \mathbf{2}^{-}, 4 \mathrm{H}, \mathrm{m}\right), 1.82-$ $1.61\left(-\mathrm{CH}_{2}-\mathrm{C}, 2 \mathrm{H}, \mathrm{m}\right), 1.62-1.59\left(\mathrm{O}=\mathrm{CCH}_{2} \mathrm{CH}_{2}, 2 \mathrm{H}, \mathrm{m}\right), 1.50-1.45\left(-\mathrm{CH}_{2}-\mathrm{CH}-\mathrm{OCH}-\mathrm{CH}_{2}-\right.$, $4 \mathrm{H}, \mathrm{m}) 1.34-1.26\left(-\left(\mathrm{CH}_{2}\right)_{6}-\mathrm{CH}_{2}-\mathrm{CH}=\mathrm{CH}-\mathrm{CH}_{2}-\left(\mathrm{CH}_{2}\right)_{4}-, 20 \mathrm{H}, \mathrm{m}\right), 1.02-0.80\left(-\mathrm{CH}_{3}, 3 \mathrm{H}, \mathrm{m}\right)$, 0.91-0.87 $\left(-\mathrm{CH}_{2} \mathrm{CH}_{3}, 3 \mathrm{H}, \mathrm{t}, J=6.8 \mathrm{~Hz}\right)$. 


\section{Results and discussion}

\subsection{Synthesis of methacrylate FA-based monomers}

Oleic acid was functionalized via Steglich esterification with 2-hydroxyethylmethacrylate (HEMA) in the presence of DMAP as catalyst and DCC as coupling agent at room temperature to afford the monomer MAEO (Scheme 1, (A)). The resulting oleic acid-based methacrylate monomer was obtained with $100 \%$ conversion and its structure was further confirmed by using ${ }^{1} \mathrm{H}$ NMR spectroscopy where all peaks have been assigned in Figure 1, (A). In the ${ }^{1} \mathrm{H}$ NMR spectrum of MAEO, the characteristic signal at $4.33 \mathrm{ppm}$ corresponds to the $\alpha-\mathrm{CH}_{2}$ of the ester functions while the vinyl protons of the methacrylate function are assigned to the peaks located at 6.12 and $5.59 \mathrm{ppm}$ and confirmed the efficiency of the functionalization. No side reaction from the oleate double bond at $5.34 \mathrm{ppm}$ has been observed.

MAEO was further epoxidized in toluene at $50{ }^{\circ} \mathrm{C}$ with formic acid, $p$ - $\mathrm{TsOH}$ as catalyst and $\mathrm{H}_{2} \mathrm{O}_{2}$ as oxidizing agent (30\% aq.) (Scheme 1, (B)). The peracids are formed in situ by reaction of formic acid with hydrogen peroxide. ${ }^{47} \mathrm{H}_{2} \mathrm{O}_{2}$ was added dropwise to the solution mixture in order to avoid substantial increase of temperature due to the exothermic reaction between $\mathrm{H}_{2} \mathrm{O}_{2}$ and $\mathrm{HCOOH} .{ }^{48}$ The ${ }^{1} \mathrm{H}$ NMR spectrum of the epoxidized MAEO is presented in Figure 1, (B). The complete disappearance of the ethylene protons at $5.34 \mathrm{ppm}$ as well as the $\alpha$-protons of the internal unsaturation of MAEO at $2.01 \mathrm{ppm}$ and finally the apparition of the $\mathrm{CH}$ protons adjacent to the epoxy group at $2.89 \mathrm{ppm}$ confirmed the successful epoxidation reaction. 


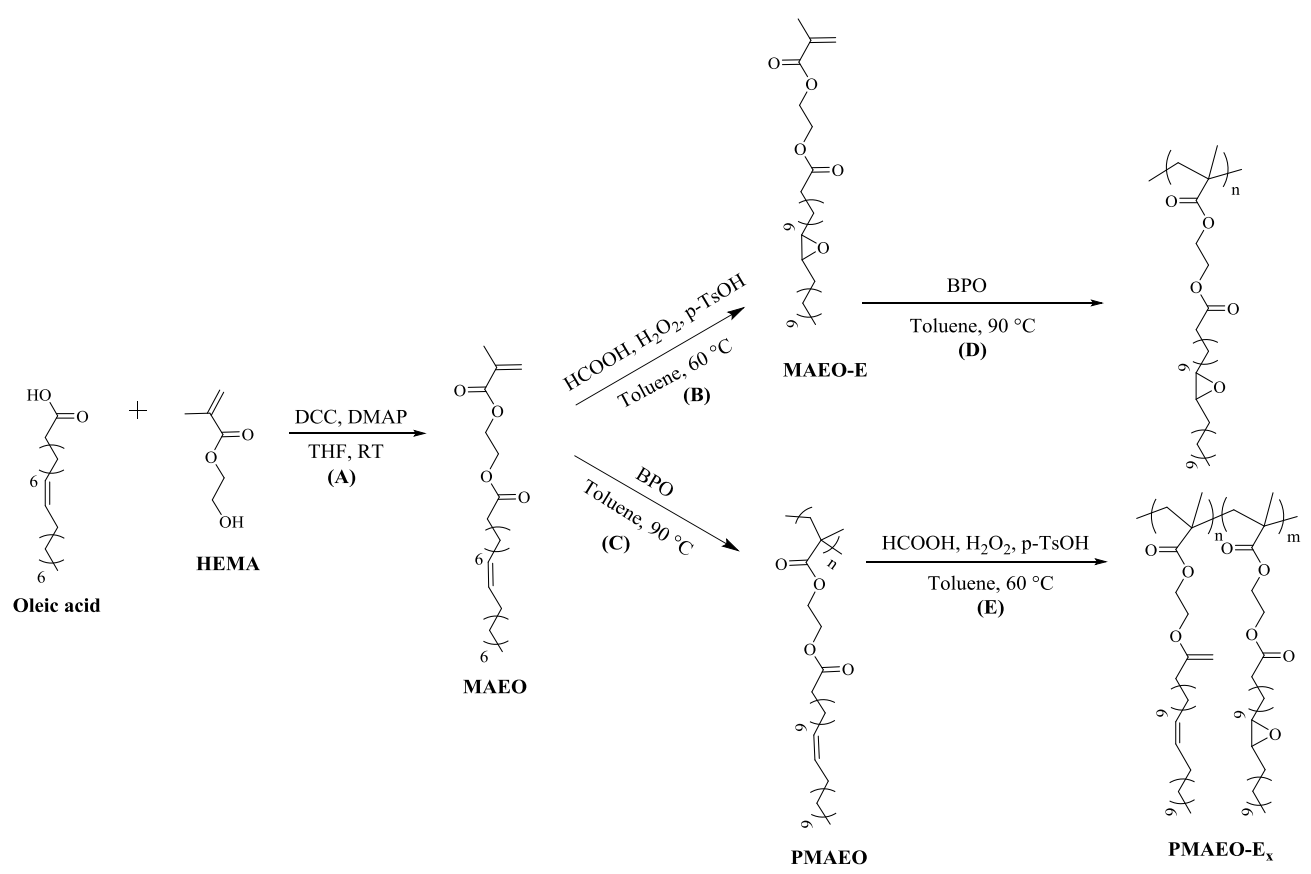

Scheme 1: (A) Synthesis of MAEO by Steglich esterification of oleic acid, (B) Epoxidation of MAEO, (C) Synthesis of PMAEO by free radical polymerization, (D) Polymerization of MAEO-E, (E) Post-polymerization epoxidation of PMAEO with $\mathrm{x}=20,30,40,50,100$ corresponding to the conversion of internal unsaturations into epoxy groups 


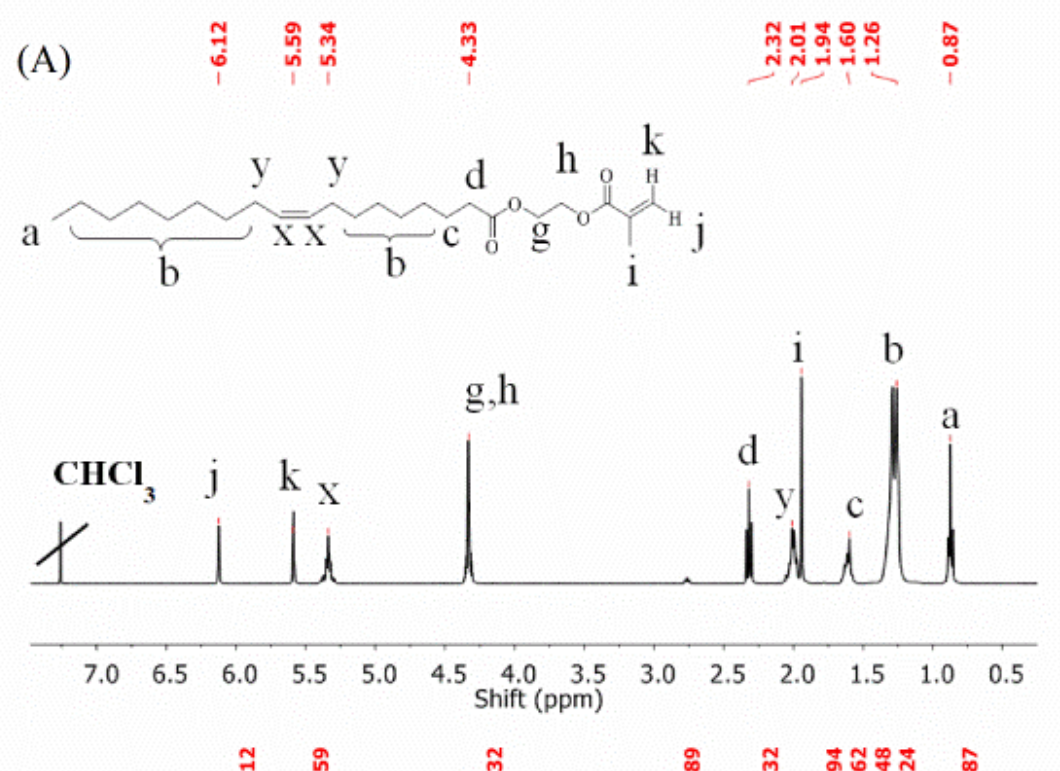

(B)
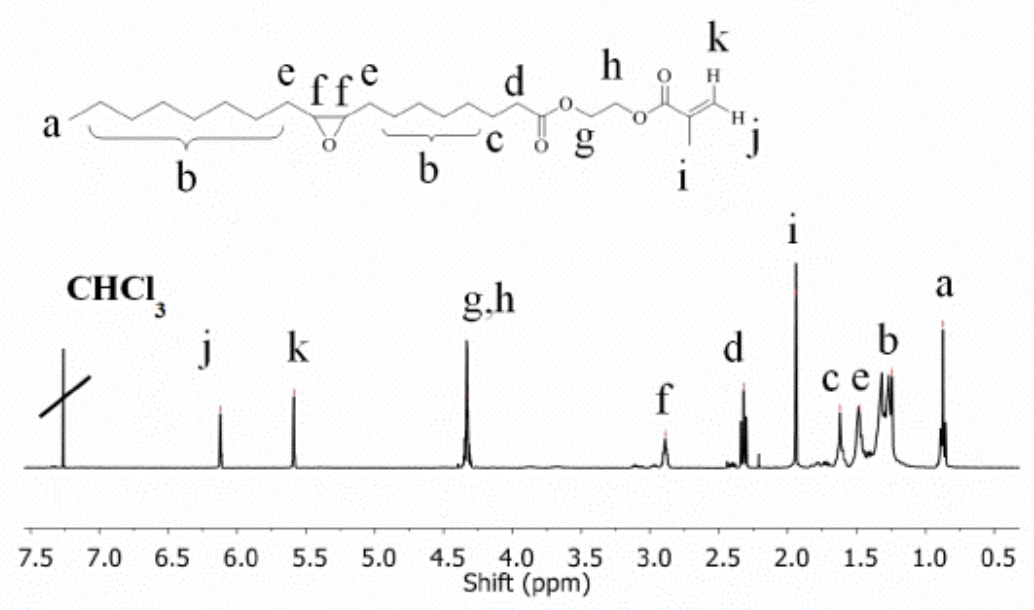

Figure 1: ${ }^{1} \mathrm{H}$ NMR spectra of (A) MAEO and (B) MAEO-E in $\mathrm{CDCl}_{3}$

\subsection{Free radical polymerization of FA-based polymers}

The polymerization of MAEO was conducted in toluene at $90{ }^{\circ} \mathrm{C}$ with $\mathrm{BPO}$ as thermal initiator (Scheme 1, (C)). The rate of polymerization was monitored by ${ }^{1} \mathrm{H}$ NMR spectroscopy by following the decrease in intensity of the methacrylate signal. The monomer was converted into polymer at $87 \%$ after $7 \mathrm{~h}$ of reaction (Figure 2). After precipitation of the resulting polymer (PMAEO) in cold $\mathrm{MeOH}$, its structure was confirmed by ${ }^{1} \mathrm{H}$ NMR (Figure 3, (A)). The peaks corresponding to the vinyl protons of the methacrylate function have completely disappeared, which confirmed the efficiency of the purification procedure. In the meantime, the signal assigned to the internal unsaturation of PMAEO at $5.33 \mathrm{ppm}$ remains constant 
revealing its unreactivity during the radical polymerization. The repeating unit protons $\mathrm{O}-$ $\mathrm{CH}_{2}-\mathrm{CH}_{2}-\mathrm{O}$ (g and $\mathrm{h}$ ) from the polymer side chain appear at 4.13 and $4.25 \mathrm{ppm}$. In addition, the spectrum indicates that chiral centers of the polymer chain present tacticity as shown by the split of the signal assigned to the methyl protons $i^{24}$ The resulting polymer exhibits a broad dispersity (3.6) and a weight average molecular weight of $160 \mathrm{~kg} \cdot \mathrm{mol}^{-1}$ determined by size-exclusion chromatography (SEC) in THF according to PMMA standards.

MAEO-E was involved in similar radical polymerization conditions than MAEO (Scheme 1, (D)). After $7 \mathrm{~h}$ of reaction, a monomer conversion of $70 \%$ was reached (Figure 2). The lower monomer conversion compared to MAEO conversion may be related to the increasing viscosity of the system as polymerization proceeds resulting in the decrease of the polymerization rate. This increasing viscosity was mainly due to the steric hindrance of the bulky and rigid pendant chains with epoxy function which are contained in the resulting polymer (PMAEO-E). Thus, PMAEO-E demonstrated lower weight average molecular weight $\left(25 \mathrm{~kg} \mathrm{~mol}^{-1}\right)$ and dispersity (1.5) than its analogous without epoxy function in the pendant aliphatic chains. However, a previous study has revealed that low polymer molecular weight did not show enough contribution on oil viscosity to show interesting VII properties in lube oils. As a result, PMAEO-E may show limited properties as VII. ${ }^{19}$ Its chemical structure was confirmed through ${ }^{1} \mathrm{H}$ NMR as shown in Figure 3, (B).

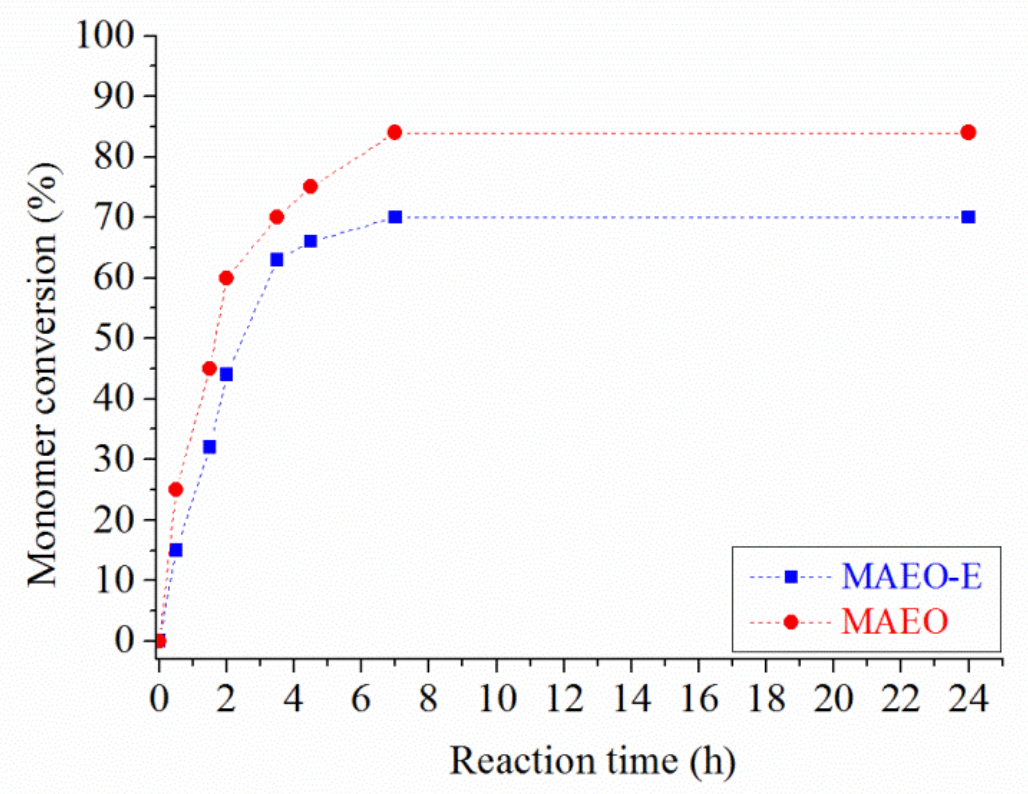

Figure 2: MAEO and MAEO-E conversion versus time during the radical polymerization 
(A)
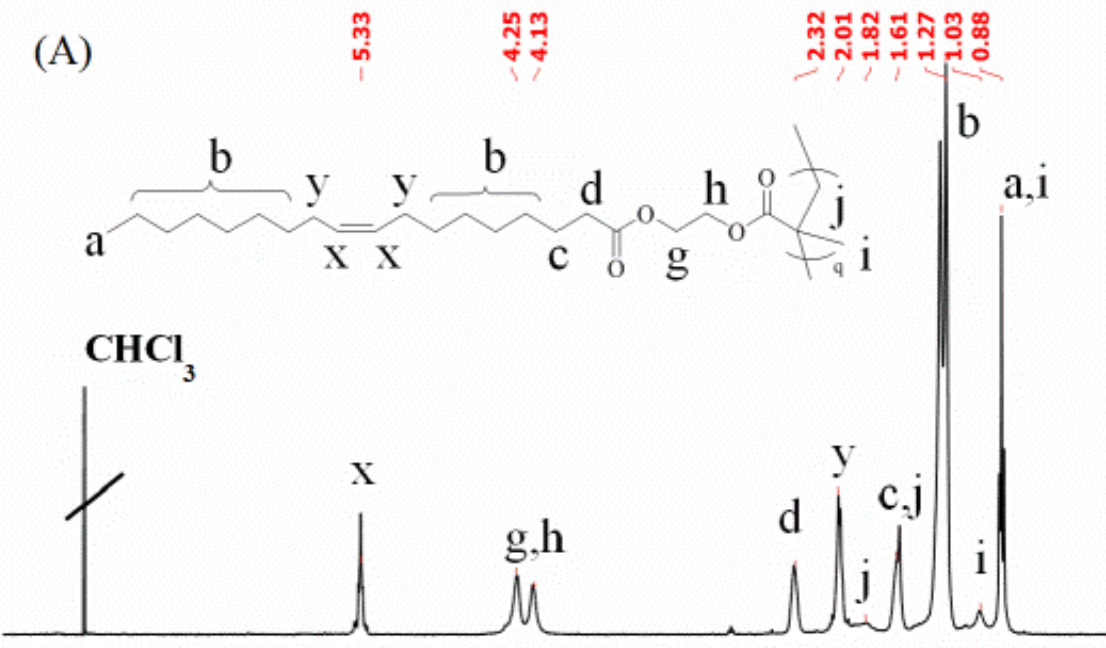

$\begin{array}{lllllllllllllll}7.5 & 7.0 & 6.5 & 6.0 & 5.5 & 5.0 & 4.5 & 4.0 & 3.5 & 3.0 & 2.5 & 2.0 & 1.5 & 1.0 & 0.5\end{array}$

(B)
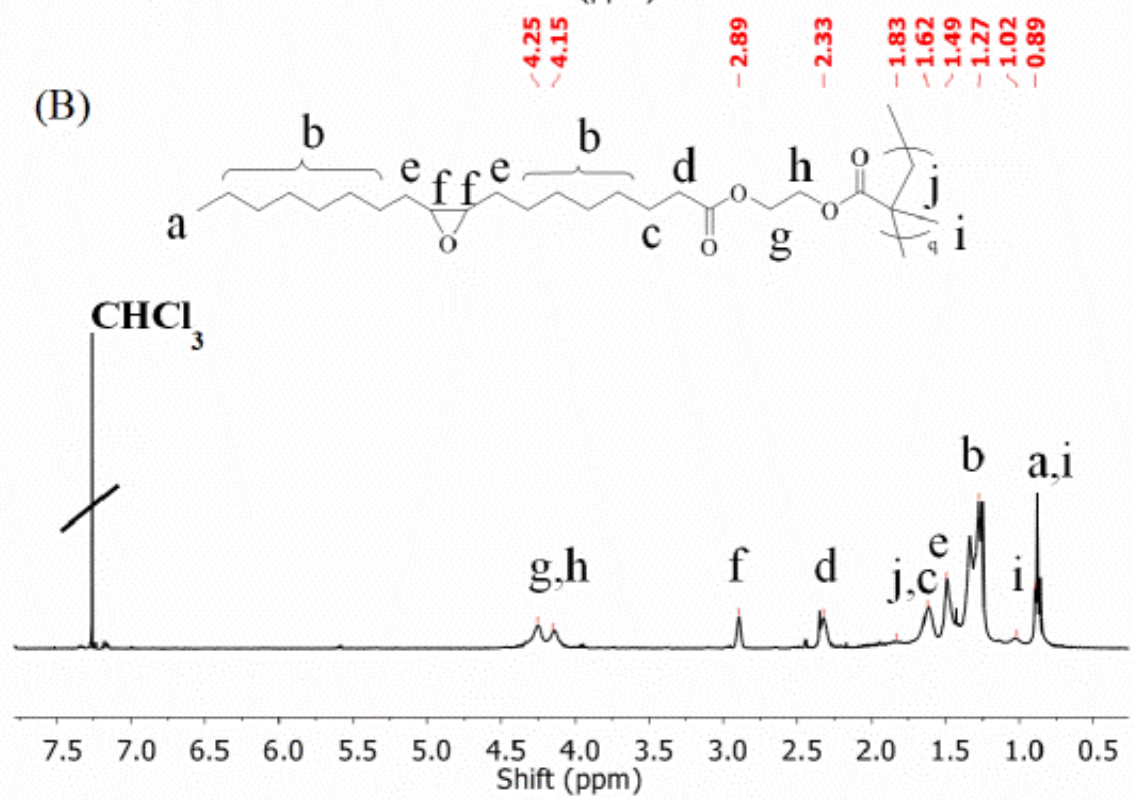

Figure 3: ${ }^{1} \mathrm{H}$ NMR spectra of PMAEO (A) and PMAEO-E (B) in $\mathrm{CDCl}_{3}$

\subsection{Post-polymerization epoxidation}

As the carbon-carbon double bond in PMAEO structure is unreactive during the radical polymerization, this reactive site is still available for further functionalizations. Therefore, epoxidation of double bonds of PMAEO has been performed to afford epoxidized polymers with different epoxy contents (Scheme 1, (E)). The double bonds of side-chains of PMAEO have been easily either partially or totally converted into epoxide groups owing to the reaction time and the amount of peracids formed in the reaction mixture. For this purpose, five molar 
ratios of PMAEO:HCOOH: $\mathrm{H}_{2} \mathrm{O}_{2}$ were studied (1:1.1:1.1; 1:0.58:0.58; 1:0.45:0.45; 1:0.38:0.38; 1:0.28:0.28). The ${ }^{1} \mathrm{H}$ NMR spectra of PMAEO-Ex with various epoxy contents are shown in Figure 4 except PMAEO- $\mathrm{E}_{100}$ which demonstrated the same NMR ${ }^{1} \mathrm{H}$ than PMAEO-E in Figure 3, (B). The epoxy protons appear around 2.9 ppm while unreacted double bonds are assigned to the peak around $5.3 \mathrm{ppm}$ confirming the partial epoxidation of PMAEO. The epoxy protons $(-\mathrm{CH}-\mathrm{O}-\mathrm{CH}-)$ relative to the unsaturation signal $(-\mathrm{CH}=\mathrm{CH}-)$ was used to calculate the degree of epoxidation (DOE) during the performed reactions according to the equation below:

$$
\mathrm{DOE}=\frac{A(-\mathrm{CH}-\mathrm{O}-\mathrm{CH}-) 2.9 \mathrm{ppm}}{A(-\mathrm{CH}-\mathrm{O}-\mathrm{CH}-) 2.9 \mathrm{ppm}+\mathrm{A}(-\mathrm{CH}=\mathrm{CH}-) 5.3 \mathrm{ppm}} \quad \text { Equation } 3
$$

The resulting conversions of internal unsaturations into epoxy groups were approximatively 20, 30, 40, 50 and $100 \%$ for PMAEO-E ${ }_{20}$, PMAEO-E 30 , PMAEO-E 40 , PMAEO- $\mathrm{E}_{50}$ and PMAEO $\mathrm{E}_{100}$ respectively. No side reactions like ring-opening reactions occurred during epoxidation.

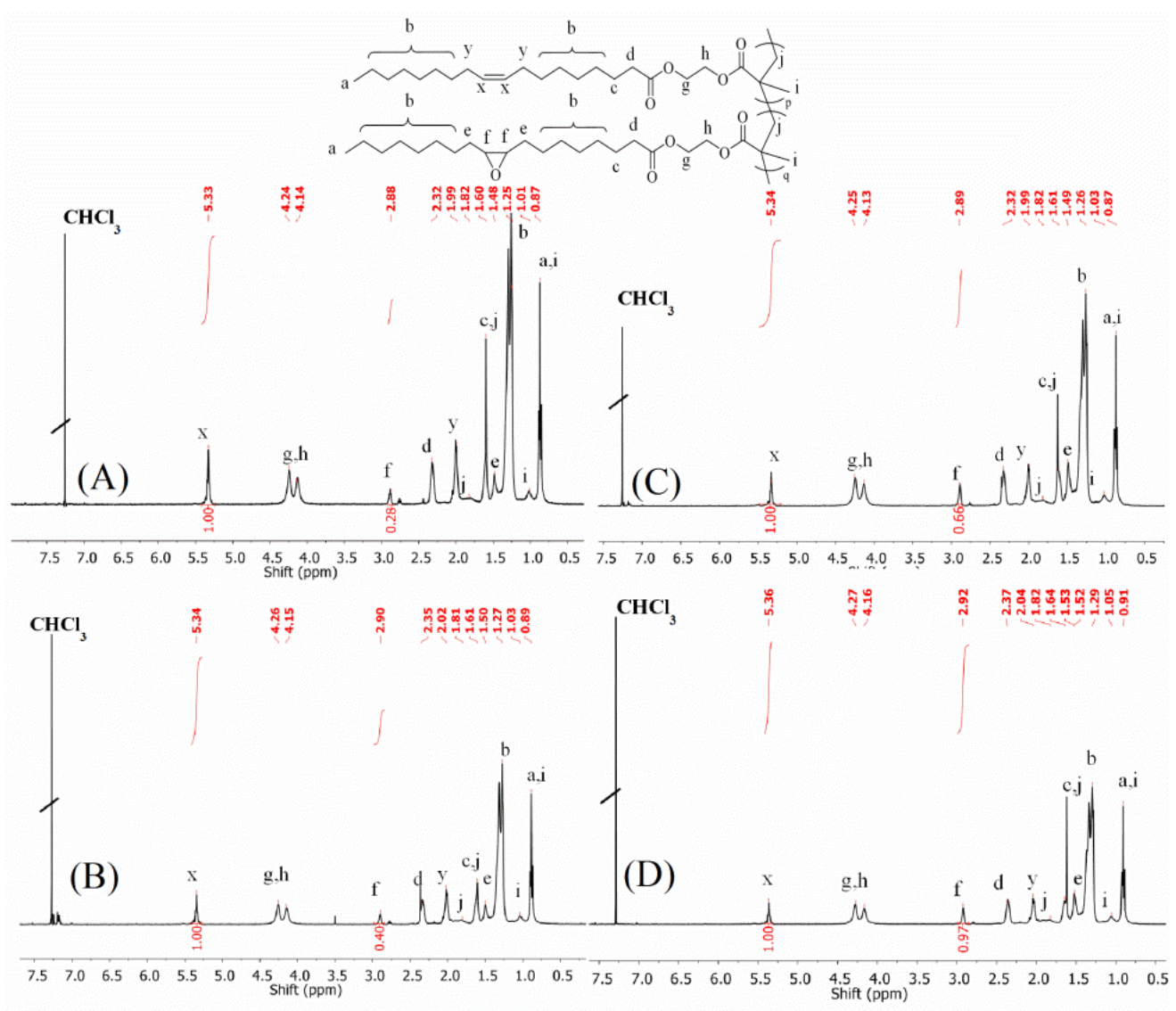

Figure 4: ${ }^{1} \mathrm{H}$ NMR spectra in $\mathrm{CDCl}_{3}$ of partial epoxidized PMAEO with (A) PMAEO-E $\mathrm{E}_{20}$ (B)

$$
\text { PMAEO-E }_{30}(\mathrm{C}) \text { PMAEO-E } 40 \text { (D) PMAEO-E } \text { P0 }_{50}
$$




\subsection{Thermal properties}

The purpose of this study was to show the suitability of the synthesized epoxized polymers from oleic acid as VII for lubricant application. Hence, as VII are supposed to be frequently subjected to high local temperatures due to their use in engine oils, the polymer thermal properties have been evaluated.

The thermal stability of all synthesized polymers were determined by TGA (Figure SI-1). Results indicated that the temperature at $5 \%$ weight loss $\left(\mathrm{T}_{\mathrm{d} 5 \%}\right)$ of epoxidized polymers increased with the epoxy content. Indeed, the $\mathrm{T}_{\mathrm{d} 5 \%}$ of PMAEO is $270{ }^{\circ} \mathrm{C}$, while they are 284 , 291, 296, 302 and $321{ }^{\circ} \mathrm{C}$ for PMAEO-E ${ }_{20}$, PMAEO-E ${ }_{30}$ PMAEO-E 40 , PMAEO-E 50 , and PMAEO-E $E_{100}$ respectively (Table 2). These results show that the presence of the epoxy ring confers higher thermal stability to the molecules in respect to alkene groups. The improvement of thermal stability of the resulting polymers with the incorporation of epoxy groups was already reported in literature. ${ }^{50}$ Moreover, for the fully epoxidized polymer, the molecular weight is not a powerful parameter since a similar thermal stability with a $\mathrm{T}_{\mathrm{d} 5 \%}$ around $320{ }^{\circ} \mathrm{C}$ was observed for both PMAEO-E (25 kg.mol $\left.{ }^{-1}\right)$ and PMAEO-E 100 (160 $\left.\mathrm{kg} \cdot \mathrm{mol}^{-1}\right)$.

Table 2: Thermal characterizations of the synthesized polymers

\begin{tabular}{ccc}
\hline Polymers & $\begin{array}{c}\text { Td5\% a) } \\
\left({ }^{\circ} \mathbf{C}\right)\end{array}$ & Tg b) $\left({ }^{\circ} \mathbf{C}\right)$ \\
\hline PMAEO & 270 & -80 \\
PMAEO-E20 & 284 & -76 \\
PMAEO-E30 & 291 & -72 \\
PMAEO-E40 & 296 & -70 \\
PMAEO-E50 & 302 & -63 \\
PMAEO-E100 & 321 & -48 \\
PMAEO-E & 318 & -50 \\
\hline a): values determined by ATG; ${ }^{\text {b) }}:$ values determined by DSC
\end{tabular}

Complementary, DSC analyses have been performed on all the polymers (Figure 5). Despite the difference of molecular weight, PMAEO-E, resulting from the homopolymerization of MAEO-E, has a similar $\mathrm{T}_{\mathrm{g}}$ value than PMAEO-E $\mathrm{E}_{100}$. PMAEO-E 100 showed a slightly higher glass transition temperature than the other partially epoxidized 
polymers as shown in Table 2. According to the results, the higher the epoxy content, the higher the rigidity of the polymer aliphatic pendant chain and the higher the $\mathrm{T}_{\mathrm{g}}$ value.

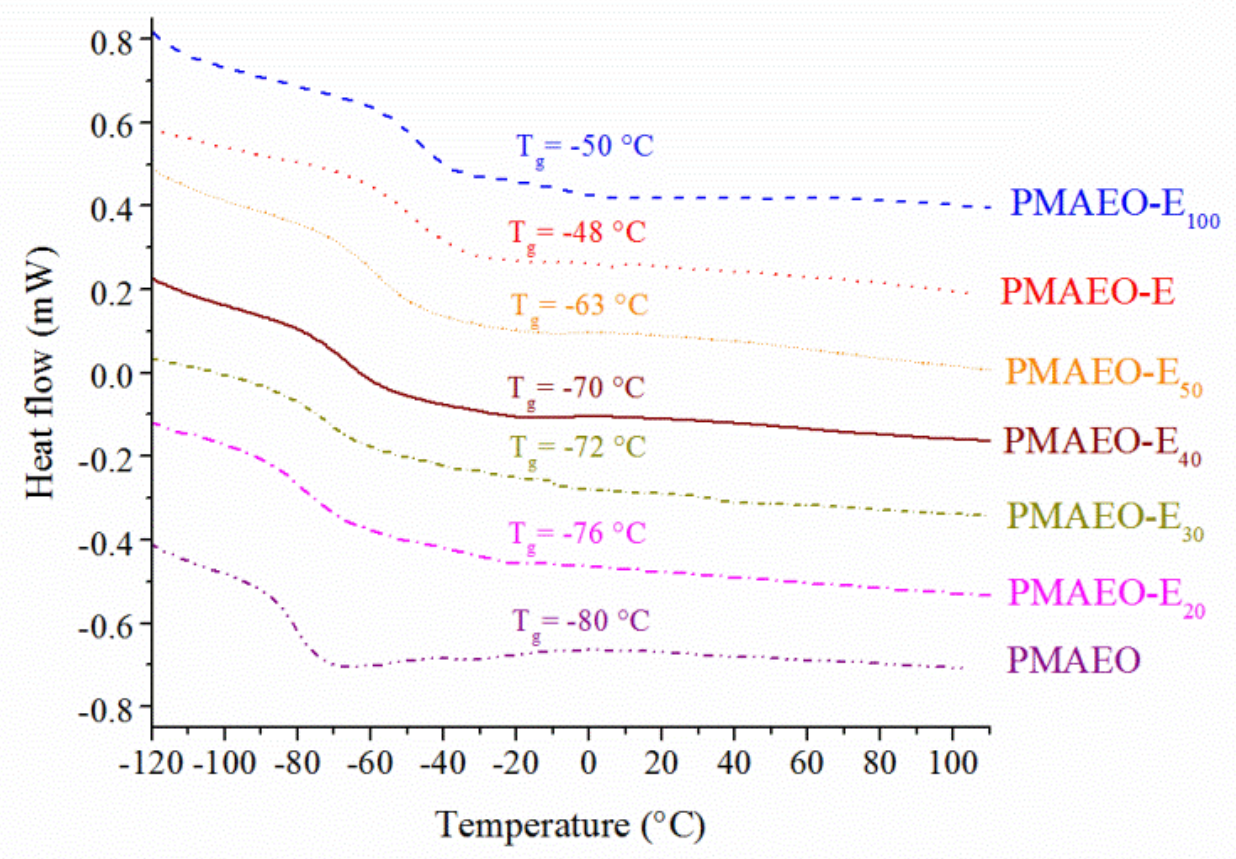

Figure 5: DSC analyses of the synthesized polymers

\subsection{Evaluation of the epoxidized oleic acid-based polymers as VII in lubricating oils}

\subsubsection{Solubility test of the resulting polymers in lube oils}

The homopolymers PMAEO-E and PMAEO-E 100 were blended at $5 \mathrm{wt} . \%$ in both organic triglyceride oil (OTO) and mineral paraffinic oil (MPO). After $1 \mathrm{~h}$ at $80{ }^{\circ} \mathrm{C}$, it was observed that they were both soluble in OTO while they were found to be totally insoluble in MPO. This difference of solubility was related to the high polarity of their epoxidized aliphatic chains which had no affinity with the high aliphatic content of MPO. Nevertheless, the insolubility of these polymers in MPO confirmed the efficiency of the epoxidation strategy; the functionalization of PMAEO with epoxy group lead to a decrease of the initial polymer solubility in MPO. On the other hand, as the triglyceride oil is less apolar than the MPO due to the presence of ester functions, it explains why the fully epoxidized polymers (PMAEO-E 
and PMAEO-E $\mathrm{E}_{100}$ ) were found to be enough soluble in this oil. In order to provide epoxidized polymers with a minimum of solubility in MPO, partially epoxidized polymers $(20,30,40$ and $50 \%$ ) were blended at 5 wt. $\%$ in MPO and heated at $80{ }^{\circ} \mathrm{C}$ for $1 \mathrm{~h}$. In this case, PMAEO-E $E_{20}$, PMAEO-E $E_{30}$ and PMAEO-E E $_{40}$ were found enough soluble in MPO to be evaluated as additives while PMAEO-E $\mathrm{E}_{50}$ was still not soluble in the oil due to its high polarity. Nevertheless, the addition of PMAEO-E ${ }_{20}$, PMAEO-E $\mathrm{E}_{30}$ and PMAEO-E 40 provided turbid oil solutions at room temperature which reflected their reduced solubility in the lube oil at low temperature. However, by heating the oil-epoxidized polymer formulations at $80{ }^{\circ} \mathrm{C}$, they became limpid and suggested a higher solubility of the partially epoxidized polymers in oil at high temperature.

\subsubsection{Rheological polymer behaviors with temperature in lubricating oils}

Rheological measurements were performed in order to evaluate the suitability of the synthesized epoxidized oleic acid-based polymers as VII for lubricating oils. For this purpose, the relative viscosity (RV) between lube oils and lube oil-polymer (5 wt. \%) blends were calculated and plotted in respect to temperature. As the calculated RV represents the influence of the polymer on oil's viscosity, the RV should increases with temperature in case of coil copolymer expansion as previously reported. ${ }^{17}$ The rheological FA-based polymers properties were compared to those previously reported for PMAEO.

\subsubsection{Mineral lube oil}

According to Figure 6, the rheological study has suggested a difference in the size of polymer coil between low and high temperatures as all the RV values of MPO-polymer blends were improved with temperature. In addition, this improvement was more significant for PMAEO-E $\mathrm{E}_{40}$ and PMAEO-E $\mathrm{E}_{30}$ compared to PMAEO. For instance, the difference of RV between 0 and $100{ }^{\circ} \mathrm{C}$ was $0.22,0.35$ and 0.55 for PMAEO, PMAEO-E 30 and PMAEO-E 40 respectively. These results were mostly explained by the higher thickening power of PMAEO$\mathrm{E}_{40}$ and PMAEO- $\mathrm{E}_{30}$ at 80 and $100{ }^{\circ} \mathrm{C}$ (where polymers are more probably in an expanded coil conformation) compared to PMAEO when blended in MPO. Indeed, the RV value of PMAEO was 1.43 at $100{ }^{\circ} \mathrm{C}$ while it was 1.55 for PMAEO-E ${ }_{30}$ and 1.75 for PMAEO-E 40 at the same temperature. These results were mostly related to the presence of epoxy functions which are known to confer rigidity to the polymers chains. ${ }^{25}$ The current literature devoted to biolubricants based on epoxidized vegetable oils report that they exhibit high VI and are 
generally used on a wide temperature range due to their higher viscosity compared to the raw oil, especially at high temperature. ${ }^{22,26}$ Our results are in total accordance with these observations. However, for low epoxy content such as the polymer PMAEO-E 20 , no significant rheological behavior differences were observed related to PMAEO. In summary, $\mathrm{PMAEO}_{40}$ and PMAEO-E 30 represent interesting alternatives to PMAEO as VII since they have a lower effect on oil viscosity at low temperature and a higher contribution on oil viscosity at high temperature.

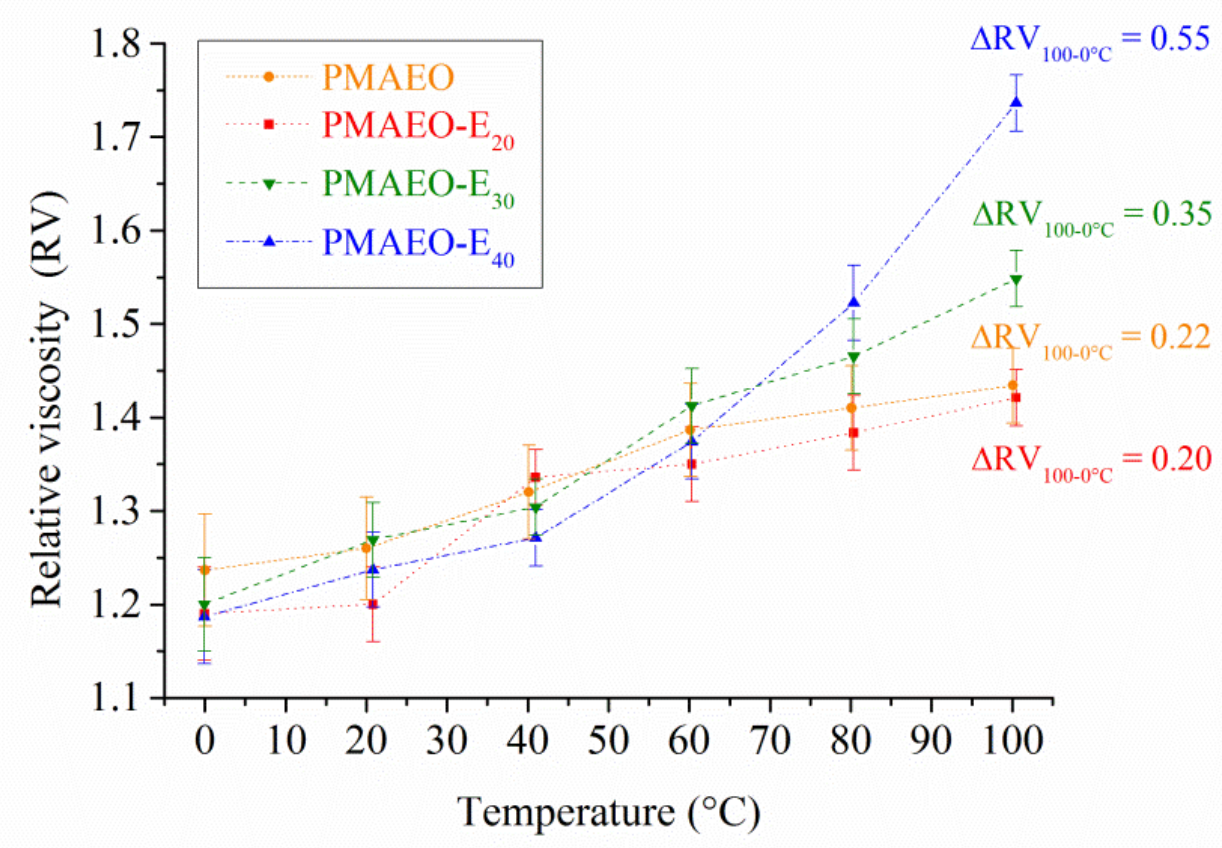

Figure 6: RV of oil-polymer blends vs temperature in MPO

\subsubsection{Organic triglyceride oil}

In a previous study, PMAEO has only demonstrated a similar thickening power with increasing temperature when added in OTO suggesting a similar coil size dimension at low and high temperatures. ${ }^{19}$ This result was explained by the good polymer solubility in OTO as they both have similar structure with long aliphatic chain and ester functions. Therefore, it may have prevented the coil expansion with temperature as the polymer was already swollen in oil at low temperature. However, when the fully epoxidized polymer PMAEO-E ${ }_{100}$ was blended in OTO, a different polymer rheological behavior on oil viscosity was clearly observed as shown in Figure 7. Indeed, while the RV remained constant with temperature for PMAEO, it was increased from 1.74 at $40{ }^{\circ} \mathrm{C}$ to 1.96 at $100{ }^{\circ} \mathrm{C}$ with PMAEO-E 100 . This result indicates that the epoxidized polymer has higher influence on oil viscosity at high temperature 
than at low temperature. Therefore, it suggests that the coil polymer size was improved by increasing temperature, inducing good polymer VII properties in OTO. Indeed, as PMAEO$\mathrm{E}_{100}$ contains non-negligible polar epoxy functions, it inherently provides less solubility in the oil at low temperature as confirmed the temperature behavior of PMAEO-E $\mathrm{E}_{100}$ in OTO which can be interpreted as a gradual increase of polymer solubility in temperature. Nevertheless, even if PMAEO-E $\mathrm{E}_{100}$ may displayed a lower solubility in OTO than PMAEO, its effect on oil viscosity was high at low temperature. This result underlined that the presence of a high content of epoxy function in the polymer backbone has also improved its thickening power compared to PMAEO.

In the meantime, the epoxidized polymer obtained via the homopolymerization of MAEOE only has shown a low and similar thickening power at low and high temperatures according to Figure 7. Indeed, the calculated RV remains constant (around 1.25) despite the increasing temperature. The difference of coil polymer behavior between PMAEO-E and PMAEO-E 100 was directly related to their high difference of molecular weights. As PMAEO displayed only a low polymer molecular weight of $25 \mathrm{~kg} \mathrm{~mol}^{-1}$, it induced a reduced coil size and a low thickening power which have limited the coil dimension improvement with temperature. Therefore, it explained the low polymer influence on oil viscosity either at low or high temperatures. These results are in accordance with our previous work where the importance of the molecular weight polymer on its VII properties were also demonstrated. ${ }^{19}$ 


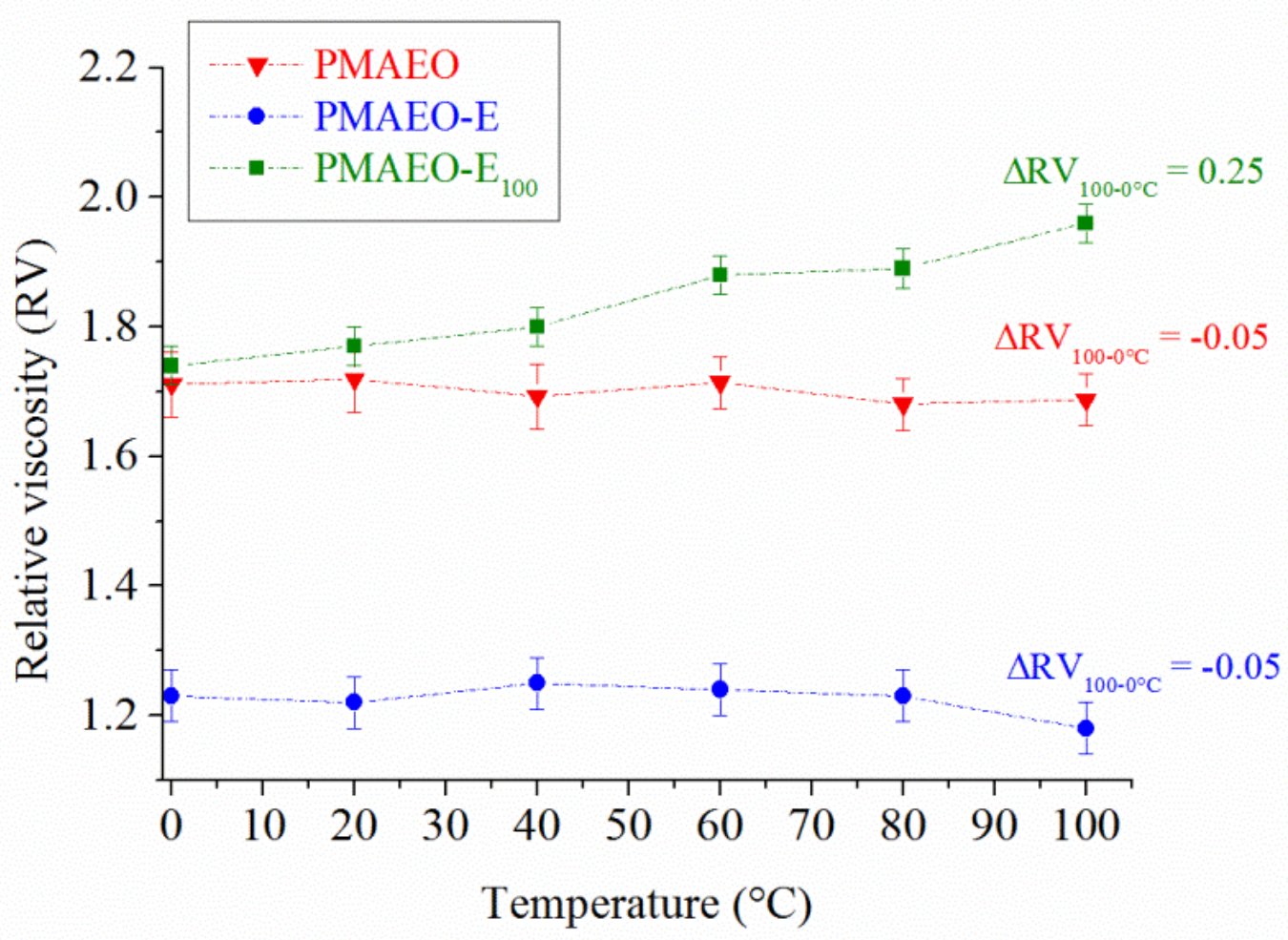

Figure 7: RV of oil-polymer blends vs temperature in OTO

\subsubsection{Viscosity Index calculations}

Viscosity Index of oil-polymer blends were measured according to the ASTM D2270-10 and compared to the initial lube oils VII. The results of Table 3 indicated that epoxidized polymers, except PMAEO-E $\mathrm{E}_{20}$, demonstrated a better ability to improve the viscosity index of MPO than PMAEO. Indeed, while the addition of 5 wt. \% of PMAEO in MPO improved the VI from 102 to 154, the addition of 5 wt. \% of PMAEO-E F $_{30}$ or PMAEO-E 40 in MPO allowed to reach a VI of 192 and 240 respectively. These results underlined the good correlation between polymers ability to have a more significant effect on oil viscosity at high than at low temperatures $\left(\Delta \mathrm{RV}_{100-0}{ }^{\circ} \mathrm{C}\right)$ and the polymer's ability to increase the oil VII. Indeed, as previously mentioned, the addition of $5 \mathrm{wt}$ \% of PMAEO-E $\mathrm{E}_{40}$ in MPO demonstrated a higher increase of $\mathrm{RV}$ with temperature $\left(\Delta \mathrm{RV}_{100-0}{ }^{\circ} \mathrm{C}=0.55\right)$ compared to PMAEO $\left(\Delta \mathrm{RV} 100-0{ }^{\circ} \mathrm{C}=\right.$ 0.20) and therefore demonstrated the best improvement of MPO's viscosity index. Consequently, the partially epoxidized polymers PMAEO-E $\mathrm{E}_{30}$ and PMAEO-E $\mathrm{E}_{40}$ exhibit better VII properties than PMAEO for MPO. 
Table 3: Viscosity index data of MPO blended with 5 wt. \% of copolymers

\begin{tabular}{ccccc}
\hline Oil-polymer blends & $\begin{array}{c}\mathbf{K V ~ 4 0}{ }^{\circ} \mathbf{C} \\
\left(\mathbf{m m}^{\mathbf{2}} \mathbf{s}^{\mathbf{- 1}}\right)\end{array}$ & $\begin{array}{c}\mathbf{K V ~ 1 0 0}{ }^{\circ} \mathbf{C} \\
\left(\mathbf{m m}^{\mathbf{2}} \mathbf{s}^{-\mathbf{1}}\right)\end{array}$ & $\begin{array}{c}\text { Viscosity } \\
\text { Index }\end{array}$ & $\Delta \mathbf{R V}_{\mathbf{1 0 0 - 0}}{ }^{\circ} \mathbf{C}$ \\
\hline Pure MPO & 26.92 & 4.87 & 102 & - \\
MPO + PMAEO & 35.80 & 6.91 & 154 & 0.20 \\
MPO +PMAEO-E & 35.81 & 6.91 & 154 & 0.20 \\
MPO +PMAEO-E & 34.99 & 7.54 & 192 & 0.35 \\
MPO +PMAEO-E & 34.18 & 8.45 & 240 & 0.55 \\
\hline
\end{tabular}

Similarly, the addition of 5 wt. \% of PMAEO-E $\mathrm{E}_{100}$ in OTO revealed a better effect than PMAEO on the improvement of the oil's VI (Table 4). Indeed, the calculated VI were 196 and 230 for respectively PMAEO and PMAEO- $\mathrm{E}_{100}$ while the pure oil was 156 . It can be noticed that despite the similar high thickening power of PMAEO on the lube oil viscosity at low and high temperatures, the polymer was still able to improve the VI of OTO. Thus, the viscosity index should not be used as the only argument to confirm the nature of an additive as suitable VII since thickener additives also have the ability to improve the oil VI without following the coil expansion theory. ${ }^{27}$ Otherwise, the addition of PMAEO-E in OTO did not affect significantly the oil viscosity index which was increased from 156 to only 162 . This observation can be directly related to the very low polymer thickening power on oil viscosity inducing low VII properties.

Table 4: Viscosity index data of OTO blended with 5 wt. \% of copolymers

\begin{tabular}{ccccc}
\hline Oil-polymer blends & $\begin{array}{c}\mathbf{K V ~ 4 0} \mathbf{~ 4 0}^{\circ} \mathbf{C} \\
\left(\mathbf{m m}^{\mathbf{2}} \mathbf{s}^{-\mathbf{1}}\right)\end{array}$ & $\begin{array}{c}\mathbf{K V ~ 1 0 0}^{\circ} \mathbf{C} \\
\left(\mathbf{m m}^{2} \mathbf{s}^{-\mathbf{1}}\right)\end{array}$ & $\begin{array}{c}\text { Viscosity } \\
\text { Index }\end{array}$ & $\Delta \mathbf{R V}_{\mathbf{1 0 0 - 0}}{ }^{\circ} \mathbf{C}$ \\
\hline Pure OTO & 26.50 & 5.58 & 156 & - \\
OTO + PMAEO & 45.32 & 9.27 & 196 & -0.05 \\
OTO PMAEO-E 100 $_{\text {OTO + PMAEO-E }}$ & 46.38 & 10.88 & 230 & 0.25 \\
\hline
\end{tabular}

\section{Conclusion}

The purpose of this study was to incorporate epoxy functions in the poly(2(methacryloyloxy)ethyl oleate) (PMAEO) backbone and evaluate the influence of such polar functions on its efficiency as viscosity index improver (VII) in both MPO and OTO lubricating oils. In a first strategy, the 2-(methacryloyloxy)ethyl oleate (MAEO) was sucessfully epoxidized and then polymerized through conventional radical polymerization. However, the resulting polymer (PMAEO-E) was obtained with a too low molecular weight for VII application $\left(25 \mathrm{~kg} \mathrm{~mol}^{-1}\right)$. Thus, a second strategy was performed using the direct 
epoxidation of double bonds of a previously reported PMAEO which displayed a suitable molecular weight for VII application $\left(160 \mathrm{~kg} \cdot \mathrm{mol}^{-1}\right)$ and which has already shown promising VII properties in MPO. Partially (20, 30, 40 and $50 \%$ of converted unsaturations) and fully epoxidized PMAEO were succesfully obtained (PMAEO-E $\mathrm{E}_{100}$ ). All the resulting polymers were firstly added at $5 \mathrm{wt}$. \% in MPO and have shown different solubilities in oil according to their epoxy content. Polymers with $50 \%$ and $100 \%$ of epoxidized unsaturations were completely insoluble in MPO while polymers PMAEO-E $\mathrm{E}_{20}, \mathrm{PMAEO}-\mathrm{E}_{30}$ and PMAEO-E 40 were found to be enough soluble in oil to be evaluated as VII. These results firstly indicated that the incorporation of polar functions in PMAEO backbone decreased its initial solubility in MPO as it was expected. Moreover, the polymers PMAEO-E $\mathrm{E}_{30}$ and PMAEO-E 40 have demonstrated a more significant improvement of their thickening power on oil with temperature compared to PMAEO. Thus, it suggested that the lower solubility of partially epoxidized polymers at low temperature in MPO compared to PMAEO allowed to improve their coil expansion with temperature and therefore their VII properties. In the meantime, the addition in OTO of 5 wt. \% of PMAEO-E 100 with a high molecular weight has shown promising VII properties that the non-epoxidized polymer did not show initially. Nevertheless, PMAEO-E showed only low properties as VII in OTO and this observation was related to its too low molecular weight for the targeted application. In summary, this study demonstrated that the control of the epoxidation rate of a high enough PMAEO molecular weight for VII application represents a promising strategy to improve its initial VII properties in mineral paraffinic oils or even to turn it into a suitable VII for triglyceride oils.

\section{Acknowledgment}

This work was performed, in partnership with the SAS PIVERT, within the frame of the French Institute for the Energy Transition (Institut pour la Transition Energétique (ITE) P.I.V.E.R.T. (www.institut-pivert.com) selected as an Investment for the Future ("Investissements d'Avenir"). This work was supported, as part of the Investments for the Future, by the French Government under the reference ANR-001-01. The authors have declared no conflict of interest. 


\section{References}

(1) Industrial and Automotive Gear Oils. In Developments in Lubricant Technology; Wiley-Blackwell, 2014; pp 161-178.

(2) Rattan, G.; Parihar, N. S. Viscosity Index Improver for Engine Oils: An Experimental Study. Journal of Chemical and Petroleum Engineering 2017, 51 (1), 39-45.

(3) Mang, T.; Noll, S.; Bartels, T. Lubricants, 1. Fundamentals of Lubricants and Lubrication. In Ullmann's Encyclopedia of Industrial Chemistry; American Cancer Society, 2011.

(4) Duggal, B. Rheology - Viscosity Index. In Encyclopedia of Tribology; Springer, Boston, MA, 2013; pp 2787-2789.

(5) Stanciu, I. Methods for Calculating Viscosity Index Hydraulic Oil. Journal of Science and Arts 2012, 2 (19), 177-180.

(6) Bataille, P.; Sharifi-Sanjani, N.; Evin, E. Preparation and Characterization of a Viscosity Index Improver for Naphthenic and Paraffinic Base Oils. Journal of solution chemistry 1994, 23 (2), 325-338.

(7) Bartz, W. J. Influence of Viscosity Index Improver, Molecular Weight, and Base Oil on Thickening, Shear Stability, and Evaporation Losses of Multigrade Oils. Lubrication Science 2000, 12 (3), 215-237.

(8) Lariviere, D.; Asfour, A.-F. A.; Hage, A.; Gao, J. Z. Viscometric Properties of Viscosity Index Improvers in Lubricant Base Oil over a Wide Temperature Range. Part I: Group II Base Oil. Lubrication Science 2000, 12 (2), 133-143.

(9) Neveu, C. D.; Sondjaja, R.; Stöhr, T.; Iroff, N. J. Lubricant and Fuel Additives Based on Polyalkylmethacrylates. In Polymer Science: A Comprehensive Reference; Elsevier, 2012; pp 453-478.

(10) Akhmedov, A. I.; Buniyat-Zade, I. A. Principles of Synthesis of Viscosity Index Improvers of the Poly(Alkyl Methacrylate) Type. Chem Technol Fuels Oils 1993, 29 (4), 207-212.

(11) Ghosh, P.; Hoque, M.; Karmakar, G.; Das, M. K. Dodecyl Methacrylate and Vinyl Acetate Copolymers as Viscosity Modifier and Pour Point Depressant for Lubricating Oil. International Journal of Industrial Chemistry 2017, 8 (2), 197-205.

(12) Jukic, A.; Vidovic, E.; Janovic, Z. Alkyl Methacrylate and Styrene Terpolymers as Lubricating Oil Viscosity Index Improvers. Chem Technol Fuels Oils 2007, 43 (5), 386-394.

(13) Ghosh, P.; Hoque, M.; Nandi, D. Homo- and Copolymers of Decyl Methacrylate as Performance Additives for Lube Oil. Petroleum Science and Technology 2015, 33 (8), 920-927.

(14) Selby, T. W. The Non-Newtonian Characteristics of Lubricating Oils. A $S L E$ Transactions 1958, 1 (1), 68-81.

(15) Müller, H. G. Mechanism of Action of Viscosity Index Improvers. Tribology International 1978, 11 (3), 189-192.

(16) Len, M.; Ramasamy, U. S.; Lichter, S.; Martini, A. Thickening Mechanisms of Polyisobutylene in Polyalphaolefin. Tribol Lett 2018, 66 (1), 5.

(17) Covitch, M. J.; Trickett, K. J. How Polymers Behave as Viscosity Index Improvers in Lubricating Oils. Advances in Chemical Engineering and Science 2015, 05 (02), 134151.

(18) Nassar, A. M. The Behavior of Polymers as Viscosity Index Improvers. Petroleum Science and Technology 2008, 26 (5), 514-522. 
(19) Lomège, J.; Negrell, C.; Robin, J.-J.; Lapinte, V.; Caillol, S. Fatty Acid-Based Methacrylate Polymers as Viscosity Modifiers for Mineral Oils. Green Materials 2018, 6 (3), 97-107.

(20) Heikal, E. K.; Elmelawy, M. S.; Khalil, S. A.; Elbasuny, N. M. Manufacturing of Environment Friendly Biolubricants from Vegetable Oils. Egyptian Journal of Petroleum 2016.

(21) Ray, S.; Rao, P. V. C.; Choudary, N. V. Poly- $\alpha$-Olefin-Based Synthetic Lubricants: A Short Review on Various Synthetic Routes. Lubrication Science 2012, 24 (1), 23-44.

(22) Erhan, S. Z.; Asadauskas, S. Lubricant Basestocks from Vegetable Oils. Industrial crops and products 2000, 11 (2), 277-282.

(23) Hörner, D. Recent Trends in Environmentally Friendly Lubricants. Journal of Synthetic Lubrication 2002, 18 (4), 327-347.

(24) White, A. J.; Filisko, F. E. Tacticity Determination of Poly(Methyl Methacrylate) (PMMA) by High-Resolution NMR. J. Polym. Sci. B Polym. Lett. Ed. 1982, 20 (10), 525-529.

(25) Yang, L.; Dai, H.; Yi, A.; Lin, B.; Li, G. Structure and Properties of Partially Epoxidized Soybean Oil. J Therm Anal Calorim 2008, 93 (3), 875-879.

(26) Trajano, M. F.; Moura, E. I. F.; Ribeiro, K. S. B.; Alves, S. M. Study of Oxide Nanoparticles as Additives for Vegetable Lubricants. Materials Research 2014, 17 (5), $1124-1128$.

(27) Martini, A.; Ramasamy, U. S.; Len, M. Review of Viscosity Modifier Lubricant Additives. Tribol Lett 2018, 66 (2), 58-72.

(28) Ghosh, P.; Karmakar, G. Evaluation of Sunflower Oil as a Multifunctional Lubricating Oil Additive. International Journal of Industrial Chemistry 2014, 5 (1), 7-17.

(29) Ghosh, P.; Hoque, M.; Karmakar, G. Castor Oil as Potential Multifunctional Additive in the Formulation of Eco-Friendly Lubricant. Polym. Bull. 2018, 75 (2), 501-514.

(30) Ghosh, P.; Upadhyay, M. Isodecyl Acrylate - Olive Oil Copolymers as Potential Biodegradable Additive for Lubricating Oil. J Polym Res 2016, 23 (5), 100-120.

(31) Montero de Espinosa, L.; Meier, M. A. R. Plant Oils: The Perfect Renewable Resource for Polymer Science?! European Polymer Journal 2011, 47 (5), 837-852.

(32) Ghosh, P.; Das, T.; Karmakar, G.; Das, M. Evaluation of Acrylate-Sunflower Oil Copolymer as Viscosity Index Improvers for Lube Oils. International Journal of Industrial Chemistry 2011, 3 (3), 547-556.

(33) Ghosh, P. Soybean Oil as a Biocompatible Multifunctional Additive for Lubricating Oil. American Chemical Society 2014, 19-25.

(34) Nasser, R. Jojoba Polymers As Lubricating Oil Additives. Petroleum and Coal 2015, 2 (57), 120-129.

(35) Dutertre, F., Pennarun, P.-Y., Colombani, O. \& Nicol, E. Straightforward synthesis of poly(lauryl acrylate)-b-poly(stearyl acrylate) diblock copolymers by ATRP. Eur. Polym. J. 2011, 47, 343-351.

(36) Maiti, B., Kumar, S. \& De, P. Controlled RAFT synthesis of side-chain oleic acid containing polymers and their post-polymerization functionalization. $R S C A d v \mathbf{2 0 1 4}, 4$, 56415-56423

(37) Maiti, B. \& De, P. RAFT polymerization of fatty acid containing monomers: controlled synthesis of polymers from renewable resources. RSC Adv. 2013, 3, 24983-24990 .

(38) Yuan, L., Wang, Z., Trenor, N. M. \& Tang, C. Robust Amidation Transformation of Plant Oils into Fatty Derivatives for Sustainable Monomers and Polymers. Macromolecules 2015, 48, 1320-1328. 
(39) Lomège, J.; Negrell, C.; Robin, J.-J.; Lapinte, V.; Caillol, S. Oleic Acid-Based Poly(Alkyl Methacrylate) as Bio-Based Viscosity Control Additive for Mineral and Vegetable Oils. Polymer Engineering \& Science 2018, No. 0. 